\title{
Exploiting Awareness for the Development of Collaborative Rehabilitation Systems
}

\author{
Miguel A. Teruel, Elena Navarro, and Pascual González \\ LoUISE Research Group, Computing Systems Department, University of Castilla-La Mancha, Albacete, Spain \\ Correspondence should be addressed to Elena Navarro; elena.navarro@uclm.es
}

Received 27 June 2017; Accepted 7 September 2017; Published 17 October 2017

Academic Editor: Pino Caballero-Gil

Copyright ( 2017 Miguel A. Teruel et al. This is an open access article distributed under the Creative Commons Attribution License, which permits unrestricted use, distribution, and reproduction in any medium, provided the original work is properly cited.

\begin{abstract}
Physical and cognitive rehabilitation is usually a challenging activity as people with any kind of deficit have to carry out tasks that are difficult due to their damaged abilities. Moreover, such difficulties become even harder while they have to work at home in an isolated manner. Therefore, the development of collaborative rehabilitation systems emerges as one of the best alternatives to mitigate such isolation and turn a difficult task into a challenging and stimulating one. As any other collaborative system, the need of being aware of other participants (their actions, locations, status, etc.) is paramount to achieve a proper collaborative experience. This awareness should be provided by using those feedback stimuli more appropriately according to the physical and cognitive abilities of the patients. This has led us to define an awareness interpretation for collaborative cognitive and physical systems. This has been defined by extending an existing proposal that has been already applied to the collaborative games field. Furthermore, in order to put this interpretation into practice, a case study based on an association image-writing rehabilitation pattern is presented illustrating how this cognitive rehabilitation task has been extended with collaborative features and enriched with awareness information.
\end{abstract}

\section{Introduction}

Health care systems are one of the main concerns of both developed and developing countries. To provide their citizens with a proper treatment becomes a must as health is usually considered one of the main pillars of their quality of life. However, offering such services at reasonable costs is not a trivial issue. In this context eHealth [1] has emerged as a proper alternative that facilitates the exploitation of technology to provide both patients and practitioners with solutions according to their specifics needs. According to Black et al. [2] eHealth technologies can be categorized into three main areas: "(1) storing, managing, and transmission of data; (2) clinical decision support; and (3) facilitating care from a distance." Among these areas, the third one, namely, telerehabilitation [3], can be considered of special interest because of the important benefits it can offer from the point of view of both patients and policymakers. First, it offers healthcare to patients at their home by using computing technologies, telecommunications, and so forth so that patients with mobility problems do not depend on their relatives to carry out their rehabilitation. Second, policymakers are able to provide more patients with rehabilitation services at reasonable costs [4].

While analyzing the literature of available rehabilitation systems, several technological challenges were detected that must be addressed. One of them is related to the diversity of deficits and diseases a patient may suffer. This means that a telerehabilitation system should provide facilities to design bespoke therapies, that is, facilities to adapt the therapy to patients' abilities, disabilities, and needs.

In addition, as aforementioned, these systems are thought to deploy the rehabilitation at patients' home, limiting their interaction with their therapists and with other patients. This means that these systems may hinder the rehabilitation process because of the isolation feeling they may cause. To mitigate such feeling, they may be turned into collaborative rehabilitation systems exploiting the concept of virtual rehabilitation rooms where they can collaborate with other peers, an important feature that recent studies, such as [5], 
have identified as key. For the design of such rooms, an important concept that must be considered from the very beginning is awareness [6]; that is, patients must be aware of who is in the virtual room, what their peers are doing, where they are, and so forth. Awareness is a concept that has been traditionally used and exploited in the development of Computer Supported Cooperative Work (CSCW) systems [7]. However, virtual rehabilitation rooms are not usual CSCW systems, but their users have their abilities hampered by some kind of trauma, congenital problem, and so forth. Moreover, their development is also highly complex, as virtual reality interfaces, haptic devices, auditory devices, and so forth are used to facilitate users' interaction and to control properly the therapy process. That is, they may be used as different communication channels to provide those feedback stimuli more appropriately according to the physical and cognitive abilities of the patients.

Different awareness interpretations have been defined so far that focus on the identification of awareness for different types of systems. However, none of them focuses on telerehabilitation systems and, thus, they do not consider important characteristics as the users' deficits. In order to address this problem, in this work a new awareness interpretation is presented. It has been defined thanks to our experience of developing rehabilitation systems during the latest years in different domains such as acquired brain injury or children with special education needs, as well as our proposals with CSCW systems. It has not been defined from scratch but extending our previous proposal in a very challenging and demanding domain: video-games development. A set of guidelines is also presented to describe how to put it into practice, as well as a case study to exemplify each awareness element identified in this new interpretation.

This paper has been structured as follows. After this introduction, Section 2 describes the related work. Then, Section 3 describes our proposal, an awareness interpretation for physical and cognitive rehabilitation systems, as well as a set of guidelines for its application. Section 4 illustrates a case study of how this proposal may be applied to design a virtual rehabilitation room. Finally, the conclusions and future work are presented in Section 5.

\section{Related Works}

The use of Information and Communication Technology advanced (ICT) proposal in the rehabilitation field is not a new approach. As Brennan et al. stated [8], the first solutions of telerehabilitation systems date back to almost forty years ago. But, although nowadays it is possible to find different commercial proposals, such as $[9,10]$, the problem has not been yet solved. The great majority of those commercial applications exhibit several limitations that motivate new researches in this area.

During these forty years of use of ICT in the rehabilitation field, several challenges have been addressed to make the most of the technology. For instance, initial proposals in the area focused on facilitating the communication between therapists and patients, such as [11] who proposed a closedcircuit television to simulate the remote communication.
Nowadays, many proposals have revolved around providing new types and complex rehabilitation tasks. For instance, it is possible to find proposals that offer therapies for the treatment of physical $[12,13]$ and cognitive diseases $[14,15]$. Moreover, because of the great diversity of diseases and deficits a patient may suffer, it is difficult to design a general solution applicable to every patient. Other factors [16] such as age, education, and experience with technology must be also considered in the design of these telerehabilitation systems. The availability of systems that therapists may use for the design of bespoke therapies emerges as a solution to address the aforementioned concerns.

Although most of these solutions have been designed to implement specific therapies [17], some of them also enable therapists to adapt some features to the patient's skills $[18,19]$ or create their own therapies from scratch. Pirovano et al. [20] make use of rehabilitation games and a fuzzy system to adapt such games according to the players' performance. They also offer certain configurability to control the physical stress of the patient. All these proposals that offer therapies adapted to the patient can improve some relevant aspects, such as user motivation and engagement [21].

Along with the need of designing personalized therapies for each specific disease, the use of multisensory feedback is also relevant for improving the rehabilitation of a specific patient as it facilitates a high number of communication channels between patient and system. Even though there are few proposals about the use of multisensory feedback in the area of rehabilitation [19], its inclusion improves the ecological validity of the therapies as the most appropriate communication channel may be selected depending on the specific patient's features. Usually, as Gutiérrez et al. [22] noticed, virtual reality (VR) environments offer a proper solution because of their capabilities to use different communication channels such as visual, aural, and haptic one. Moreover, the exploitation of different channels also helps to enhance how realistic a virtual environment is perceived by the user [10]. For example, the use of haptic sense could enable the transmission of some alerts or information for improving the completion of the task requested [23].

Furthermore, as Cranen et al. claim [24] some of the main advantages of using ICT in the rehabilitation process is to reduce the number of visits to the care center, increase the time available for the therapies, and decrease the treatment costs. However, they also identify some problems resulting from this teletreatment. Namely, patients miss the presence of the therapist and are less motivated when they need to carry out complex exercises. Patients also remark another problem related to their social isolation. Therefore, an advantage as a reduced number of visits to the care center may become a problem, because the direct interaction with therapists and with other patients is also reduced.

In order to mitigate these isolation problems, some authors offer video conference solution $[8,25]$ and others [26] integrate some social networks in their telehealth systems for improving the interpersonal communication. However, few proposals offer social interaction through some collaborative features that enable patients to collaborate while they carry out a specific therapy [21, 27]. Moreover, similarly to real 
environment, other people could play a relevant social role in such collaborative therapies: observers and motivators. Observers are people who are not doing the therapy but provide some social interaction with the patient. Not only do motivators observe the therapy but they can also cheer the patients up by using their voice or making some gestures that patients could perceive. Usually, these observers and motivators are the relatives of the patient, or some specialists.

The introduction of collaborative features entails the use of concepts already applied in the design of Computer Supported Collaborative Work (CSCW) or groupware systems [28]. One of the main CSCW concepts is awareness that has been defined as "the up-to-the-moment understanding of another person's interaction within a shared workspace" [6]. In a previous work [29] the available awareness interpretations (collaboration awareness, situation awareness, workspace awareness, context awareness, social awareness, and so on) were analyzed concluding that it is not possible to cover all the features of modern complex collaborative systems by using just only one of them. To solve such problem a thematic analysis was conducted that led to the definition of Gamespace Awareness that integrates the existing proposals in order to guide in the specification of the awareness of one of the most complex collaborative systems: collaborative video-games. In addition, in the telerehabilitation domain some other elements should be taken into account, such as how to provide users with the necessary feedback while they are carrying out their rehabilitation tasks. Therefore, in this work, based on these needs already identified in [30] and our previous proposal [29], we propose an awareness interpretation to be used in the design of collaborative physical and cognitive telerehabilitation systems, identifying both which awareness elements may be of interest and which stimuli may be used to interact with patients making the most of their rehabilitation process.

\section{Awareness Interpretation for Physical and Cognitive Rehabilitation Systems}

The awareness interpretation developed to deal with the awareness features of telerehabilitation systems for physical and cognitive therapies is presented next. This interpretation has been defined by adapting Gamespace Awareness [29] to make it suitable for this kind of systems.

Table 1 presents the elements identified for this awareness interpretation. They are categorized into four different concerns related to either the temporal stages the awareness is related to (present, past, and future) or those related to social and group dynamics. Within each concern, each awareness element is classified depending on what awareness information they are providing. For instance, within the present concern, the awareness elements deal with who is participating, what and where they do anything, and how to do it. Aimed at helping designers to identify the awareness needs of a rehabilitation system, a set of questions have been defined along with these awareness elements. For instance, consider a remote physical rehabilitation system whose patients have to work in a collaborative manner. In order to perform such collaboration, they must be aware of who is available to collaborate with while performing the rehabilitation session, what the other patients are doing to coordinate their actions properly, where they are located in their own space, and how to interact with them. This awareness information, which is easily perceived in a nonremote and computerless rehabilitation environments, is key when collaborating remotely. Consequently, this new awareness interpretation aims at making remote rehabilitation as straightforward and fruitful as face to face rehabilitation.

As shown in Table 1, for each awareness element, it has been also defined which feedback stimuli could be used to provide participants with the required awareness, that is, visual (by means of a computer screen or a virtual reality headset), aural (by playing sound or audio messages), or haptic (by receiving vibrations on different parts of the body). Furthermore, when dealing with disabled people, providing awareness information through different stimuli is paramount since certain stimuli may not be received or understood by disabled users. For example, when a deaf patient is using a telerehabilitation system, audio messages may be replaced with visual notifications or haptic signals. However, not all awareness elements can be properly provided by using any stimulus. As an example, making the participants aware of the log-in of a new user in the system (element Identity) by using haptic feedback would not be practical since it would require codifying each new participant ID as different haptic signals. This would cause that our users were overwhelmed due to the constant vibrations received, and it would be difficult to implement as the number of users increases. Nevertheless, providing the same awareness information through an audio message (e.g., "John is now online") is comprehensible by most of the participants.

Table 1 also presents several examples of how each awareness element could be implemented, that is, how to gather such awareness information and how to provide participants with it. For instance, the status element, which is related to the participant's physical and emotional status could be obtained by using either a biometric sensor that gathers physical data such as heat rate or skin conductance [31], or a camera along with an emotional analysis software to analyze participants' emotions [32]. Moreover, this awareness information may be provided by using different stimuli. For instance, if it was required to make a participant aware of other participants' heart rate, this awareness information could be provided by using the three considered stimuli. Firstly, visual stimuli may be easily used by playing animated heartbeats on the screen, thus representing the heart rate of the remote participant. Secondly, aural stimuli can also be considered and implemented by playing heartbeats though audio. Finally, it could be also possible to use haptic stimuli as well, thus emulating heartbeats by sending haptic impulses that the participant will feel on a specific part of his/her body.

3.1. How to Put into Practice the Awareness Interpretation. Once the awareness interpretation has been presented, it will be explained in the following how to put it into practice. For this aim, let us start from the specification of the tasks of a rehabilitation system to be developed. To perform such specification, any requirement engineering specification 


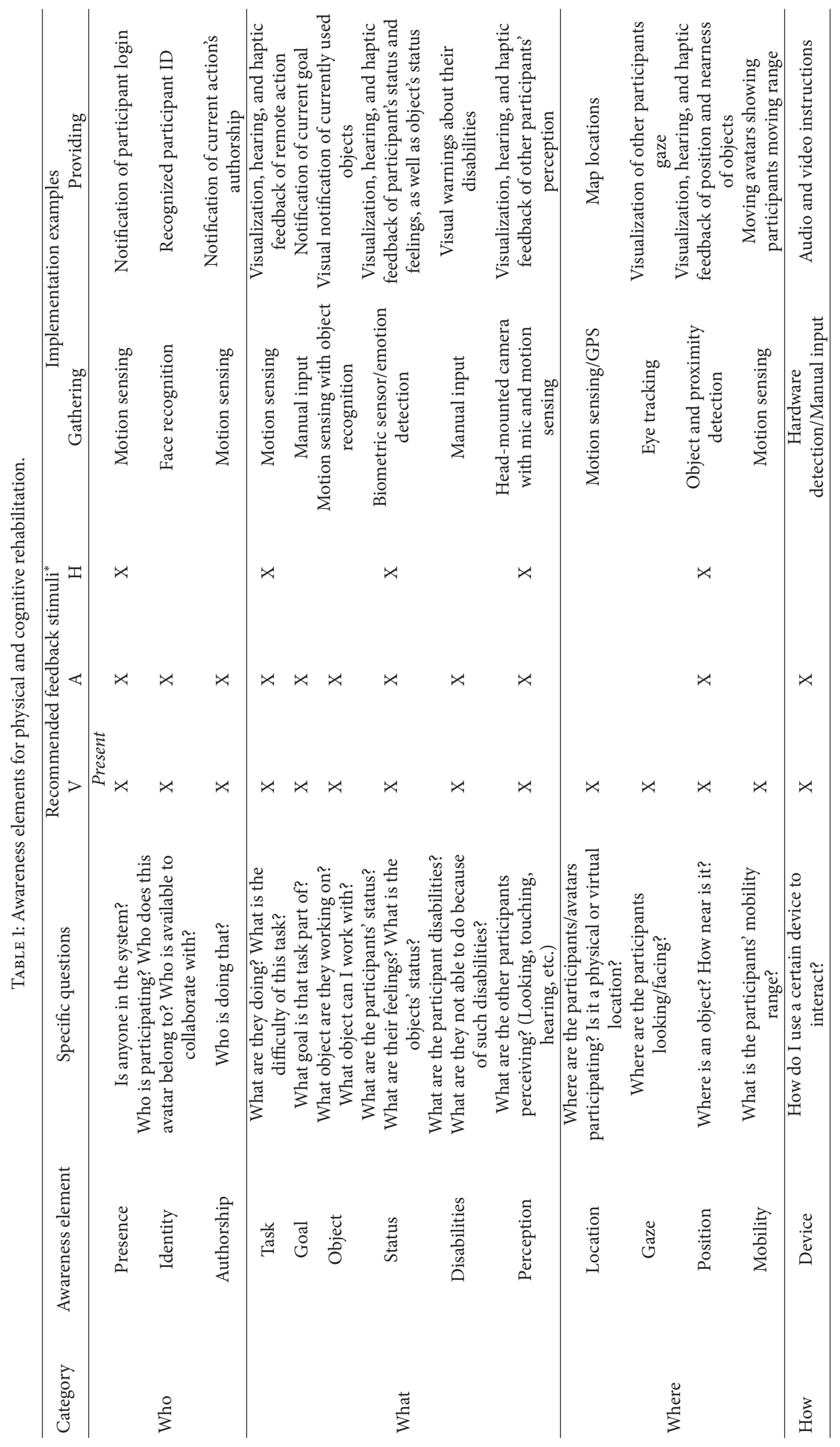




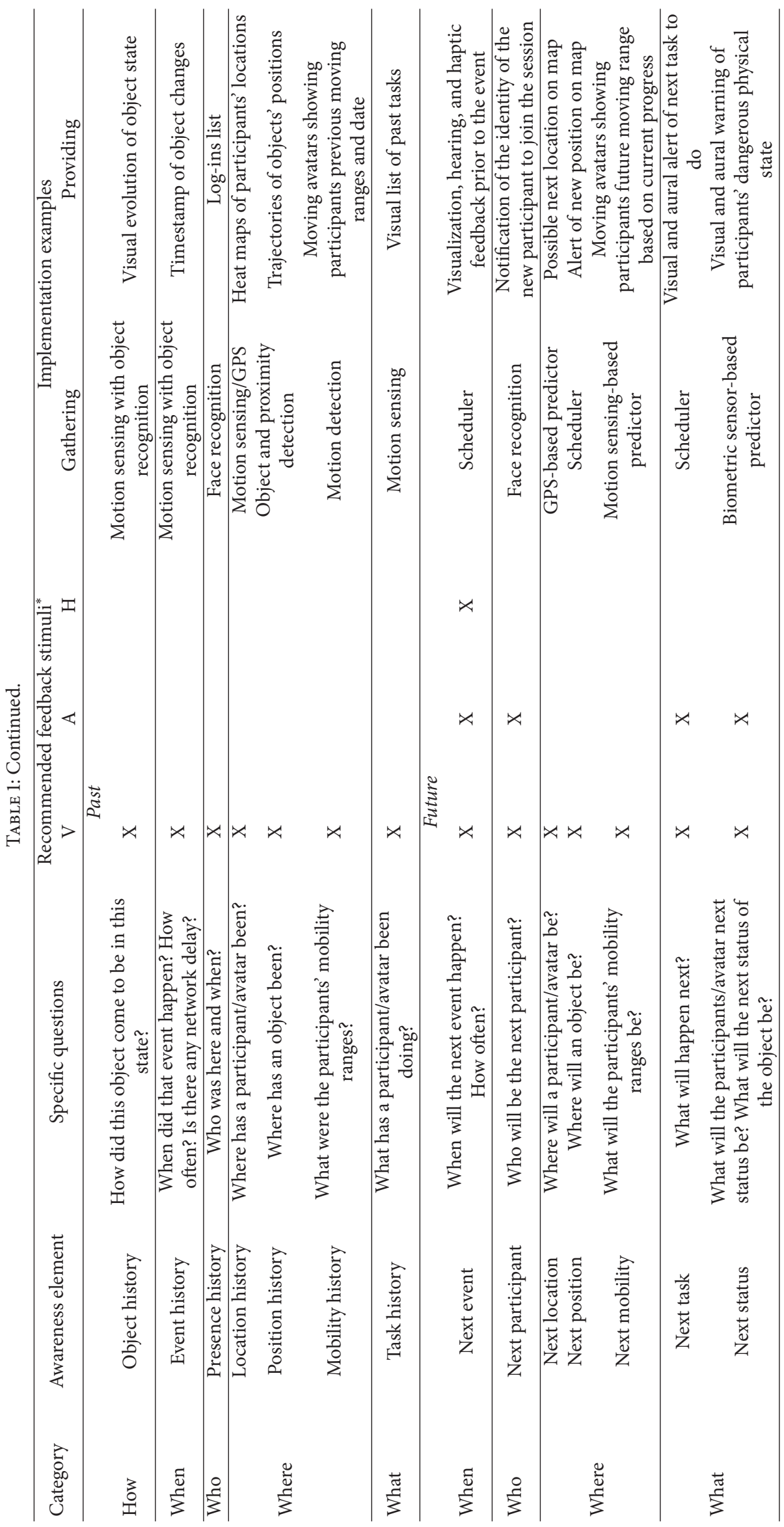




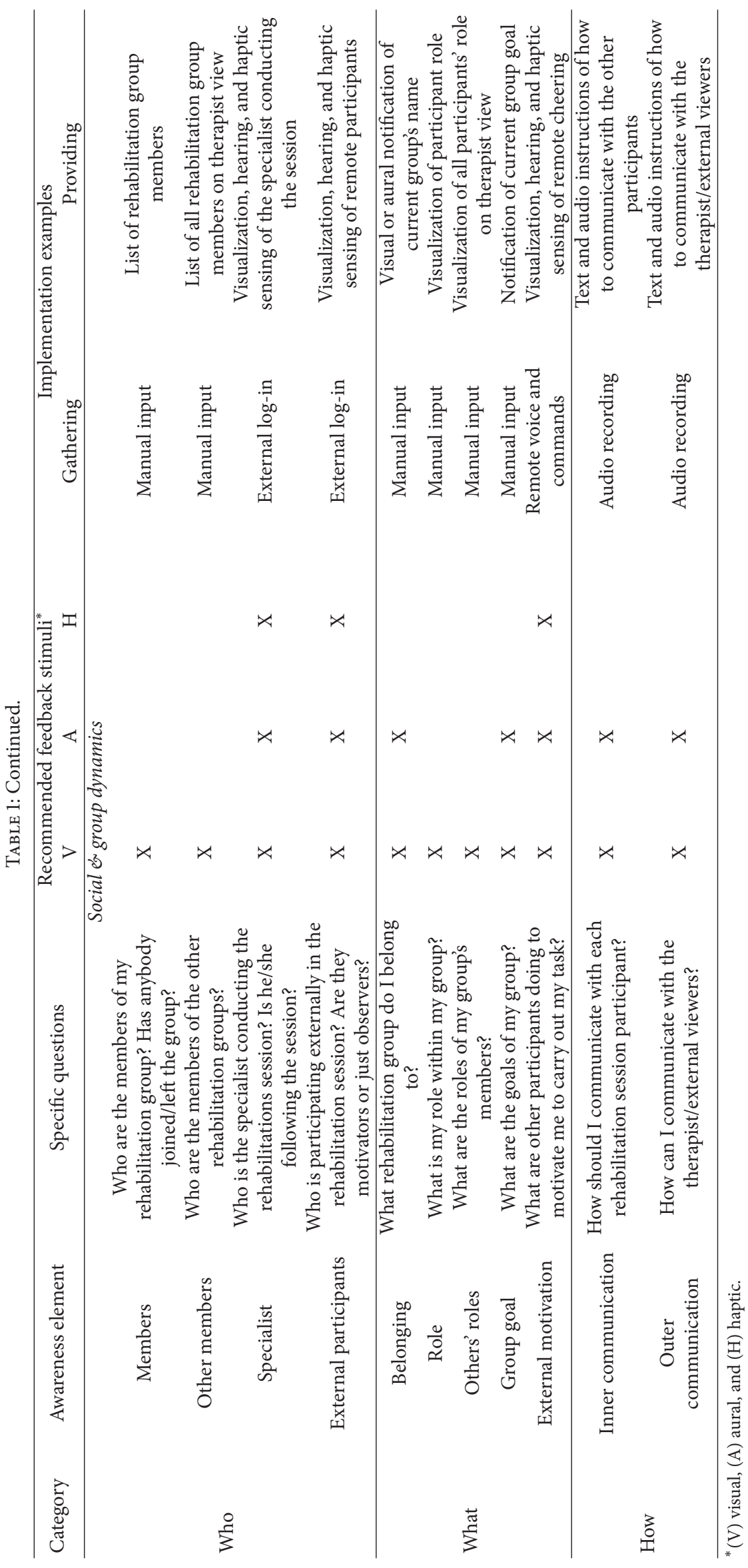




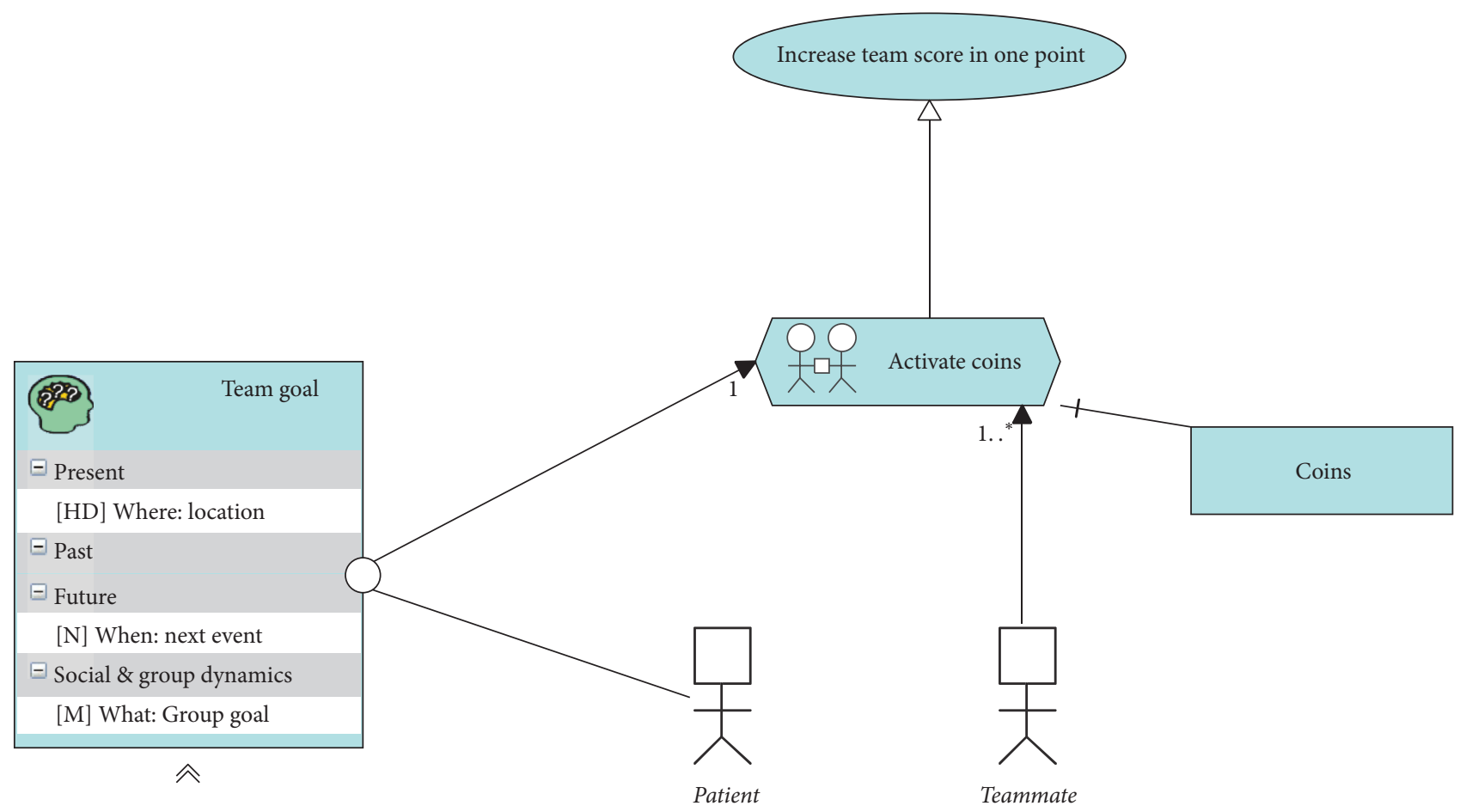

FIGURE 1: Example of CSRMF diagram specifying a collaborative task with awareness needs. * means $N$; that is, from 1 to $N$ teammates can be related to activate coins.

technique may be used. However, due to its collaboration and awareness modelling capabilities, we recommend using the Collaborative Systems Requirements Modelling Framework (CSRMF) [33].

Once the tasks of the system have been specified, those awareness features considered necessary to ease the interaction between the user and this system can be defined. For this aim, Table 1 provides a set of questions that will help us to identify the awareness needs of our system. As an example, let us consider the first awareness element on Table 1, PresentWho-Presence. Such element includes the specific question "Is anyone in the system?" Therefore, to assess whether or not this awareness element should be included among our system's requirements, we would ask ourselves "Do our users need to know if there is anyone in the system?" If so, this awareness element will be included among our system's requirements. In Table 1, Present-Who-Presence, such element includes the specific question "Is anyone in the system?" Therefore, to assess whether or not this awareness element should be included among our system's requirements, we would ask ourselves "Do our users need to know if there is anyone in the system?" If so, this awareness element will be included among our system's requirements.

Once we are in the design phase of the system, the stimuli to provide each awareness element must be specified. With this aim, Table 1 also includes the recommended feedback stimuli column that suggests what stimuli may be used to communicate the awareness information. For instance, the presence element could be offered by using visual, aural, or haptic stimuli (or a combination of them). Table 1 has the recommended feedback stimuli column that suggests what stimuli may be used to provide the awareness information. For the considered presence element, it could be provided by using visual, aural, or haptic stimuli (or a combination of them). Moreover, Table 1 also includes implementation examples for each awareness element. In this case, the information to provide the presence element may be gathered by employing a motion-sensing device when it detects that there is a new user in the scenario, provided by notifying the log-in of a new participant using a visual message, playing a log-in sound, or sending a haptic signal.

Figure 1 shows a different example of how to model a task and specify its corresponding awareness needs by using CSRMF. This is a collaborative task whose participants, namely, a player and his/her teammates must activate several coins in a virtual world to fulfil their goal: increase the team score one point. For this aim, it is mandatory $(\mathrm{M})$ that such player be aware of what the coin he/she has to activate, that is, what the group goal is. Moreover, it is highly desirable (HD) to know where the other players are located in the virtual world. Finally, it would be nice to have $(\mathrm{N})$ information about when the next event will happen, that is, when new coins will appear. This task will be implemented in the case study that will be presented in Section 4.4.

\section{Case Study}

In the previous section, an interpretation aimed at identifying the awareness requirements of a rehabilitation system was presented. Therefore, to put it into practice, this section presents a case study based on a physical-cognitive collaborative rehabilitation exercise. Aimed at making the 


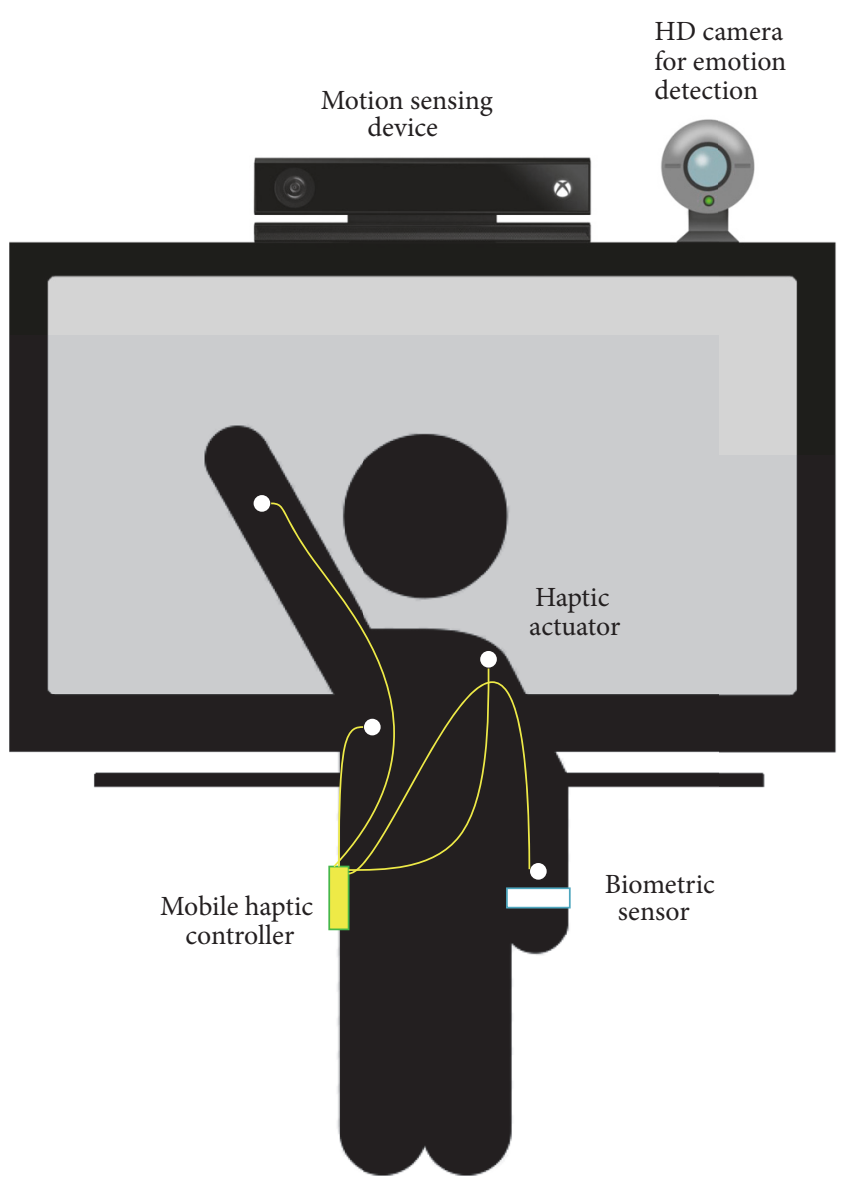

FIGURE 2: Participants' hardware environment.

performance of such exercise enjoyable, it will be presented as a game whose users will play collaboratively yet remotely grouped in several teams. In this game, patients will be represented as avatars. Hence, to interact with this game when performing the exercise, a motion-sensing device will be used to translate the participants' movements into avatars movements. Figure 2 exemplifies how the hardware environment for this rehabilitation system could be. A motion-sensing device such as Microsoft Kinect [18] will gather the participants' movements. Besides, a high definition camera will capture the users' face and forward it to an emotional analysis SDK [32] that will analyze and interpret their emotional status. A wristband will also interpret their emotional status measuring their heart rate. This physical and emotional information will be sent to the therapist to follow the evolution of the patients. Finally, a wearable haptic controller with several actuators will be used to make the user feel certain events of the game. Hence, 4 actuators will be used, located on both patients' hands (to feel the game objects), chest (to feel heartbeats), and shoulder (to feel encouragement pats).

As far as the cognitive rehabilitation exercise is concerned, it is based on an association image-writing rehabilitation pattern. This pattern is defined in [34] as an exercise to improve patients' front executive capability.

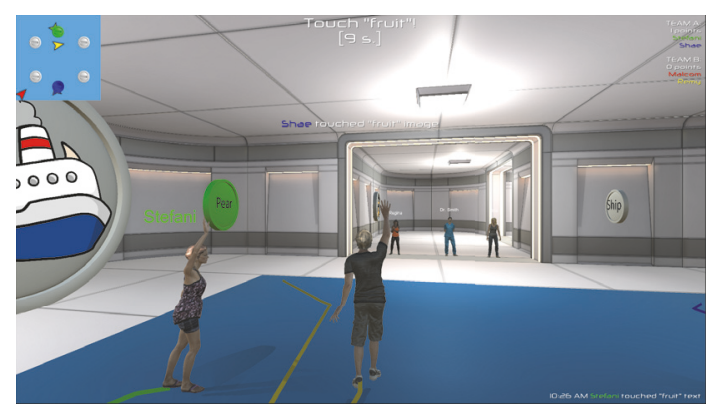

FIgURE 3: Prototype of participants' user interface (patient's avatar located in the center of the interface using a third-person view).

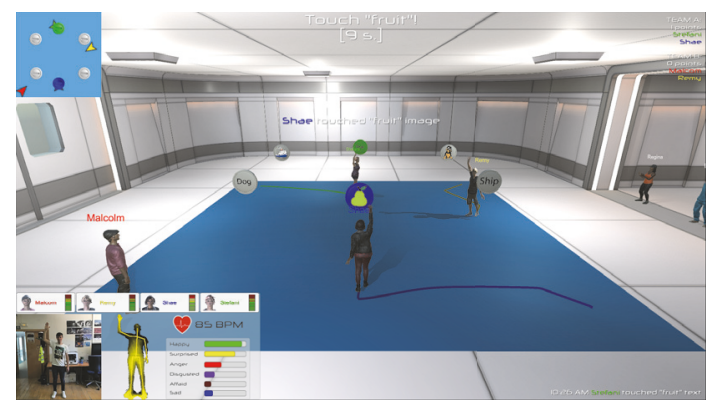

FIGURE 4: Prototype of therapist's user interface.

Regarding the game itself, the participants' avatars will be in a virtual world where several coins with images and words on them will be scattered around the game field. Therefore, the implementation of the aforementioned rehabilitation pattern consists in asking the teams of participants to find and touch a virtual coin related to a specific concept. As an example, if the system request is to find and touch the "fruit" coin, one participant will have to touch the coin with the image of a pear on it; meanwhile the other does so with the coin showing the word "pear." Figure 3 illustrates two different avatars. The avatar controlled by the current player is trying to activate a coin; meanwhile the green player has already activated the "pear" coin.

Besides, regarding physical rehabilitation, the therapist will be able to place the coins in different locations to encourage the participants' displacements and movements. For instance, if a participant needs an upper limb rehabilitation therapy, the therapist could locate the coins in a high position, so that the participant will have to lift his arm to activate such coin. Moreover, the size of the game field can be customizable according to the movements requirements of the therapy to be performed. For instance, if a patient could not walk, all the coins would be located around the avatar to avoid displacements over the game field.

Furthermore, the therapist will have a different view of the system (see Figure 4) to monitor the therapy execution, enabling her to see each participant view, the participants themselves, as well as their emotional status (obtained by using a facial analysis software).

Finally, external participants (neither patients nor specialists) can participate into the system. Specifically, these 


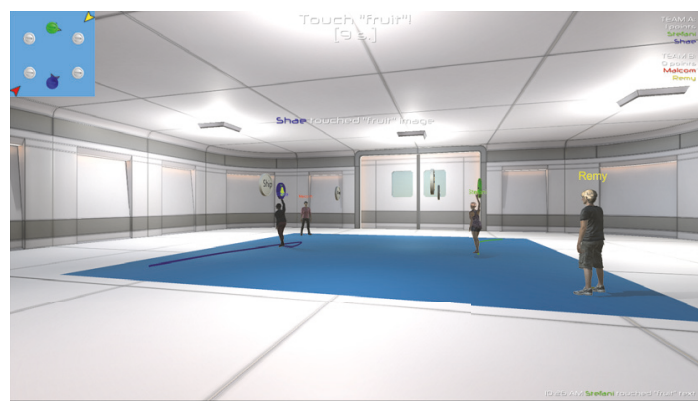

FIgURe 5: Prototype of observer's user interface.

external participants will adopt the role of observers and motivators. Hence, observers can watch the rehabilitation session (see Figure 5). Besides, motivators can also cheer the patients up by using their voice that patients may hear during the rehabilitation session. It is worth noting that both observers and motivators, as well as therapists, will be also represented in the game by using avatars to make patients aware of the presence of such participants (see Figure 3).

Aimed at exemplifying how the awareness interpretation presented in Section 3 could be used in the design of such rehabilitation exercise, in the following it is explained how several awareness elements could be implemented and presented to the participants for the recommended feedback stimuli described in Table 1. Notice that several elements could not be implemented in this case study since they are not suitable for this exercise. For instance, in this game every participant has the same responsibilities within his/her team, without having a specific role. Consequently, the role and others' roles awareness elements were not used.

4.1. Present. The first awareness elements are those related to what is happening in the rehabilitation session at the very moment of its performance, namely, the present. Hence, the implemented elements belonging to such concern are the following ones:

(i) Presence. Participants have to be aware of the presence of a new participant with whom to collaborate. Following the suggested implementation described in Table 1, the exercise could be implemented according to the following requirements: when a motionsensing device detects a new participant, the system will provide the already-connected participant (if any) with a haptic stimulus indicating the presence of a teammate with whom to perform the rehabilitation session. Therefore, it would not be necessary that a logged-in participant is continuously looking at the screen to know whether there is another user in the virtual rehabilitation room, being warned with a vibration on his wrist when the session is ready. However, this awareness information could also be provided by means of visual (by showing the participant's avatar) or aural signals to indicate a new log-in into the system. (ii) Identity. Participants have to be aware of which participant is related to which avatar. With this aim, each participant's avatar will have a tag with the participant's name over the head (Figure 6). Moreover, each participant name will have a different color aimed at easing the visual identification of participants.

(iii) Authorship: Participants have to be aware of who activated a coin in the virtual world. The requirement would be the following: the color of such coin (visual representation) could change to match the color of the participant's avatar. As an example, Figure 3 shows that the pear (image) coin has been touched by the blue player.

(iv) Task. The therapist must be aware of what the participants are doing. It could be achieved by means of a visual remote view (Figure 4) to observe both what the participants are doing in the virtual room (through their avatars) and the real world (real streamed video of the participants). To reinforce this feedback, an aural message such as "Malcom has activated the dog coin" or a haptic signal representing a coin activation could be sent to the participants.

(v) Object. Participants have to be aware of the coin that they as well as the other participants have activated. For instance, similarly to the authorship awareness element, the color of the coins (visual representation) could provide awareness information regarding what object they are interacting with. However, different sounds (aural representation) could be associated with the coins that will be played when they are touched, thus helping the participants to identify them. For instance, if a participant activated the "dog" coin, a dog bark could be played though the audio system. Finally, in order to make a participant aware of the fact that the target coin has been activated, not only will it change its color according to the participant's color, but also he/she will receive a long haptic signal on the hand he/she activated the coin with.

(vi) Status. The therapist has to be aware of both the participants' heart rate and emotional status. To implement this awareness element, the participants' heart rate and emotional status could be presented in a visual manner (Figure 4) to the therapist who would be able to interrupt the session or adjust if needed. For instance, if a participant's heart rate was considerably high or he was in a bad emotional state, the therapist could interrupt the session and adapt it according to the participant's needs. The heartbeats of the participants could be coded into aural beats or haptic vibrations to make them aware of their own heart rate, that is, of their own physical status.

(vii) Disabilities. The system has to be aware of any participant's disabilities in order to avoid and/or adapt the stimuli provided. Prior to start a session, the therapist will indicate whether any participant have disabilities to configure the system. For instance, if a participant 


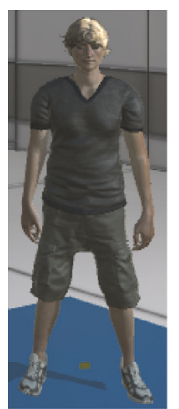

Presence

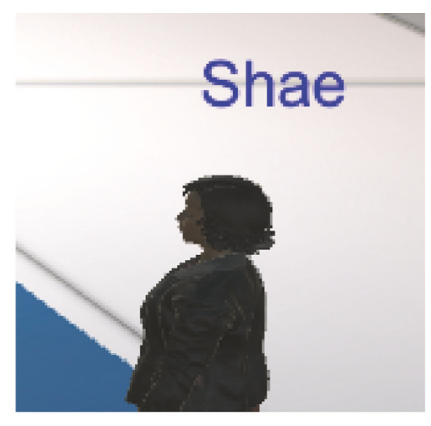

Identity

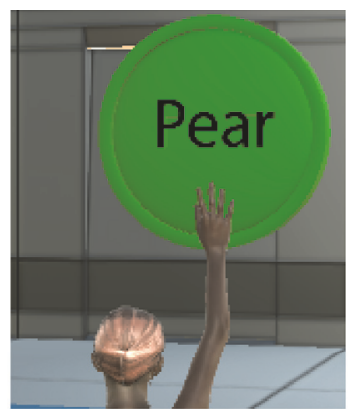

Authorship

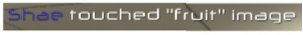

Task and object

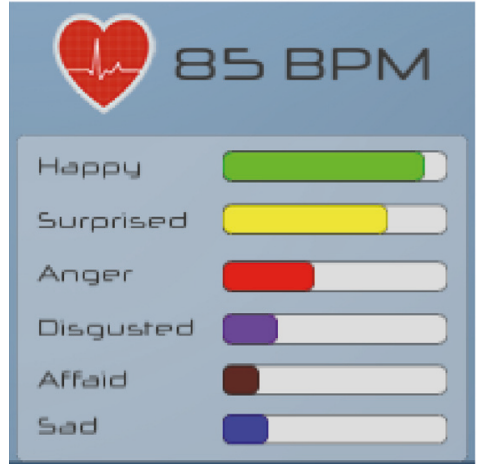

Status

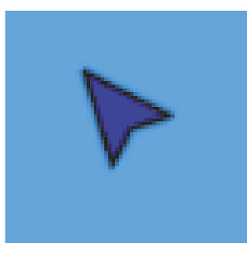

Location and gaze

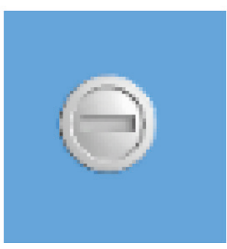

Position

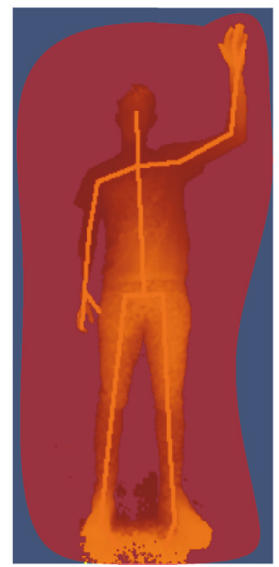

Mobility

FiguRE 6: Visual implementation of present awareness element.

is deaf, audio messages will be presented by using visual closed captions. Besides, blind participants may interact with the system by receiving aural messages about the coins' location. Moreover, if a participant is unable to walk, all the coins will be located within the participant's reach area.

(viii) Location. The participants have to be aware of their locations. The patient will know such location by looking at a visual map of the scenario (top-left corner of Figure 3). Moreover, by looking at this map, he may obtain information about the position of the other participants. It is worth noting that this map may represent the participants as arrows with the same color as the participants' name.

(ix) Gaze. The direction each participant is facing can be seen in the map by means of the arrows representing the participants (Figure 6). In this sense, the arrow will point towards the direction where the participant is facing. However, if the therapist had to be aware of where the participants are looking to detect cognitive problems, an eye-tracking system could be implemented. For instance, the therapist could see the point of the screen where the participants are looking on the therapist's view in a visual manner. Therefore, if a participant was constantly looking at a screen point where no coin or participant was located, a cognitive issue could be identified. (x) Position. Participants must be aware of the position of the coins. Similarly to what happens with the location element, participants may know the position of the elements by using this visual map (top-left corner of Figure 3). Thanks to this awareness feature, the participants could be aware of the presence of coins positioned behind them that cannot be seen in a 3D third-person view. For a more detailed analysis of the difference between location and position please refer to [29]. To reinforce this feedback, the concept of nearness to the coin could be represented as aural messages with a variable pitch or increasing the haptic signal depending of such nearness.

(xi) Mobility. The therapist has to be aware of what the participants' can reach or where they can move. For example, the therapist may see a visual representation of each participant's reach area on a postsession screen (see Figure 4). This image could be generated based on their previous movements. Therefore, the therapist will analyze if the physical rehabilitation process has been successful by measuring a possible enlargement of such reach areas (i.e., the participants are able to reach further with their limbs than before starting the rehabilitation process). This image could be generated based on their previous movements. Therefore, the therapist will analyze if the physical rehabilitation process has been successful by 
10:26 AM Stefoni touched "fruit" text

Event and task history

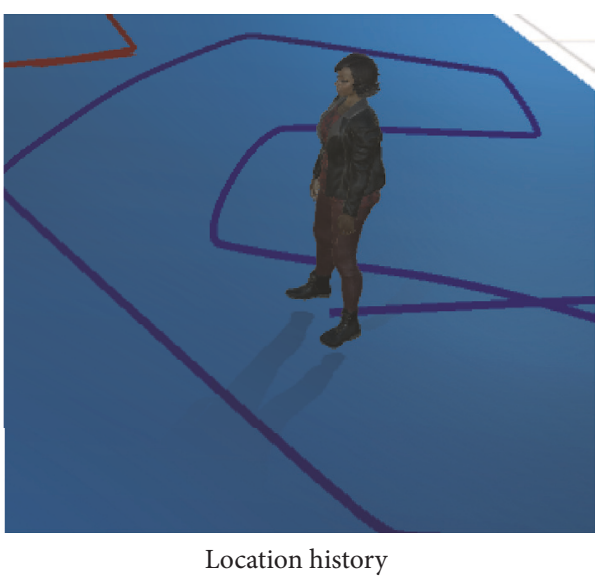

Location history

FIgURE 7: Visual implementation of past awareness element.

TABLE 2: Examples of present awareness elements implemented through aural messages.

\begin{tabular}{lc}
\hline Awareness element & Aural message example \\
\hline $\begin{array}{l}\text { Presence } \\
\text { Identity } \\
\text { Task and object } \\
\text { Object } \\
\text { Status } \\
\text { Position } \\
\text { Shae has joined the game } \\
\text { Mevice }\end{array}$ \\
$\begin{array}{l}\text { Malcom has activated the dog coin } \\
\text { [Dog bark] }\end{array}$ \\
[Heartbeat $]$
\end{tabular}

measuring a possible enlargement of such reach areas (i.e., the participants are able to reach further with their limbs than before starting the rehabilitation process).

(xii) Device. Participants have to be aware of how to interact with the system. For instance, the interaction with the system in this case study will be performed by means of the motion-sensing device. Therefore, if the system detects that a participant was not aware what he has to do, a visual or aural message would be displayed or played, respectively, thus informing such participant about how to interact (Table 2).

4.2. Past. Once the awareness elements related to the present have been presented, those related to the past will complement the participants' awareness with information about facts that happened prior to the current time:

(i) Object history. Once the session is finished, a postgame interface could provide detailed information of the different states each coin had had. In other words, this will implement a log detailing the interaction of participants with the game coins.

(ii) Event history. The game interface will show the exact time when something happened. This information will be reflected in the actions log located at the bottom-right corner of the interface (see Figure 3).

(iii) Presence history: The presence of participants in the system will be logged to be queried by the therapist when required. Hence, the system will record both the log-in and log-out time of each participant. With these data, the therapist could analyze whether or not the participants have been performing their assigned therapies regularly.

(iv) Location history. To make both participants and therapist aware of the previous location of a participant's avatar, they will leave a trail behind as they move around the game field (see Figure 7). This trail will have the same color of the participant's name, and the time that it will remain shown can be configured.

(v) Position history. This awareness element will complement object history by adding information about where each coin appeared. In this sense, the game log will also include the position of each coin in the map. This could be implemented graphically (indicating the position of the coins by using a map) or textually (just by indication of the coordinates of the position of each coin in meters, departing from the center of the game field).

(vi) Mobility history. Closely related to the mobility element from the present concern, the mobility history can represent the evolution of the patient's mobility over time. In this sense, it can be analyzed how the patient's mobility range has been evolved from the very beginning of the rehabilitation therapy. Therefore, the therapist can assess whether or not the therapy has been fructiferous for each patient.

(vii) Task history. The system will record and show all the tasks performed by the participants. Therefore, a task history will be shown in the bottom-right corner (see Figure 3). It is worth noting that, in order to ease the identification of participants in this list of tasks, each name will be colored according to the participant's color. 
TABLE 3: Examples of future awareness elements implemented through aural messages.

\begin{tabular}{lc}
\hline Awareness element & Aural message example \\
\hline Next event & Next coin in 9 seconds \\
Next participant & A new participant will join team 1 in 15 seconds \\
Next mobility & After this session, your right arm mobility could improve $2 \%$ \\
Next task & The next coin will be “Animal." Get ready! \\
Next status & [Warning sound] \\
\hline
\end{tabular}

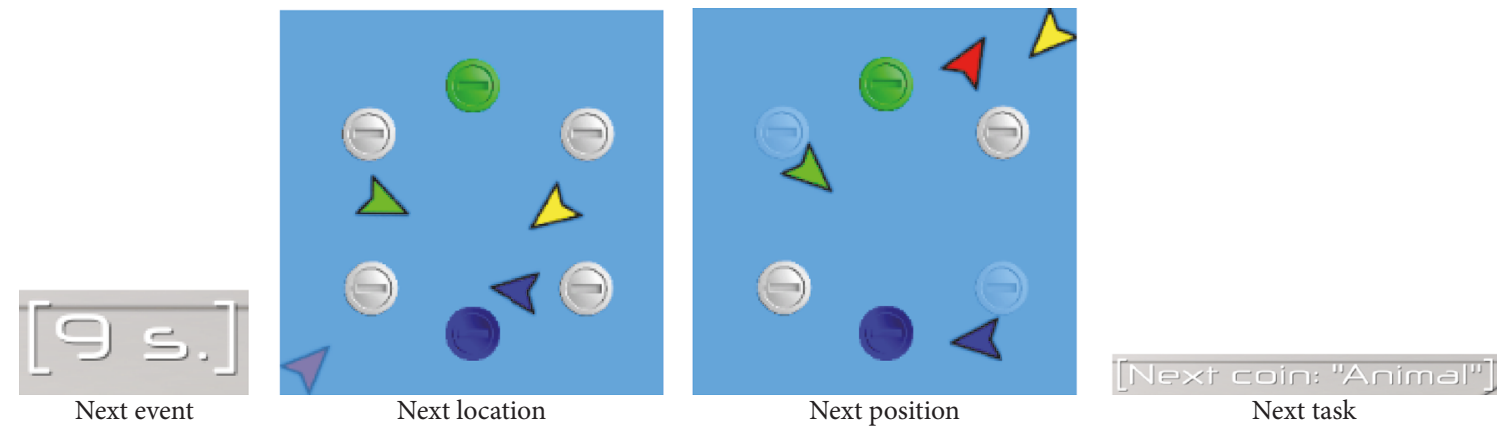

FIGURE 8: Visual implementation of future awareness element.

4.3. Future. Next, we will deal with those awareness elements related to the future. Such elements make the participants be aware of something that will happen in a near future which could affect the current development of the rehabilitation session somehow. The future awareness elements are the following ones:

(i) Next event. In order for the participants to anticipate their actions, this element will provide them with information about what the next event will be. In this example, this element will show the remaining time that a new coin will appear in the game field (see top of Figure 3).

(ii) Next participant. During a game, no new participants can join it. However, when a new coin is going to appear, a new participant can join the game, sending an audio message to the current participants (Table 3 ). Hence, they will be aware that a new participant will join the game soon, as well as what team he/she will be part of.

(iii) Next location. Related to the previous awareness element, prior to the appearance of a new participant, his/her starting position can be signaled on the map (Figure 8). In this sense, not only will current participants be aware of an upcoming new participant, but they will also know where he/she will be located initially.

(iv) Next position. Similar to the previous element, when a new coin is going to appear, it could be signaled on the map so that participants get ready to touch such coin (Figure 8). Thus, they could anticipate the appearance on this new coin moving towards the new position where it is supposed to appear. (v) Next mobility. Based on mobility history, the system could analyze the progression of the patients' mobility over time. Therefore, the system could predict what the future mobility of the user will be if he/she keeps on following the rehabilitation session. This information can be used to motivate patients prior to the performance of a new session by making them aware of what they can achieve during the next sessions.

(vi) Next task. The element next event was used to make participants aware that a new event will happen. Complementarily, such awareness information can be enriched by adding details of such event. In this example, this information could advance the next task that participants will have to perform, namely, the coin that they will have to touch next.

(vii) Next status. This awareness element could be used to make a patient (and the therapist) aware that he will be in a specific emotional or physical state based on past measurement. As an example, if the participant is having a high heart rate in combination with a negative emotional status (sad or disguised), the system could recommend that he/she suspend the rehabilitation session.

4.4. Social and Group Dynamics. Finally, the last awareness elements are related to a nontemporal concern, namely, social and group dynamic. Hence, the elements belonging to this last concern are the following ones:

(i) Members. The participants will be able to know who is participating in their team at any time during the rehabilitation session. With this aim, a list of players belonging to his/her own team will be shown on 
TABLE 4: Examples of social and group dynamics awareness elements implemented through aural messages.

\begin{tabular}{lc}
\hline Awareness element & Aural message example \\
\hline $\begin{array}{l}\text { Specialist } \\
\text { Belonging }\end{array}$ & This session is being supervised by Dr. Smith \\
Inner communication & You will play as a member of team 2 \\
Outer communication & You can always communicate with your therapist by using your voice Let him know if you have any problem \\
while performing the therapy
\end{tabular}

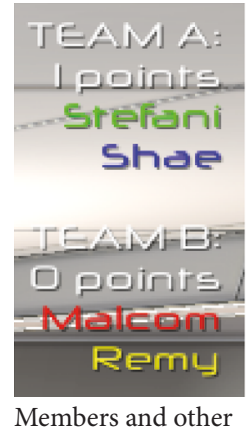

members

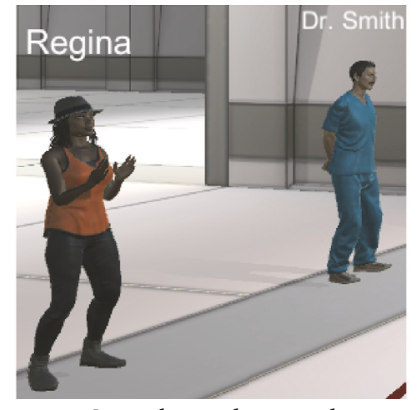

Specialist and external participants

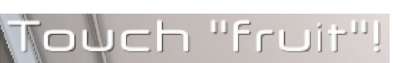

Group goal

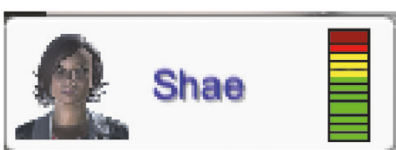

Outer communication

Figure 9: Visual implementation of social and group dynamics awareness element.

the participant user interface (see top-right corner of Figure 3). Moreover, to ease the identification of team members, the name of the teammates on this list will be colored with each participant name color.

(ii) Other members. As happened with the previous awareness element, a different list will show the members of the rival teams with their corresponding character colors (see top-right corner of Figure 3).

(iii) Specialist. The participants will be able to know who is the therapist conducting the session. Moreover, to recreate a real scenario, an avatar representing the therapist will be included in the game interface, also showing the therapist's name (Figure 9).

(iv) External participants. During the sessions, two kinds of external participants are allowed to interact, namely, observer and motivators. The former will be able to watch the session; meanwhile the latter can also cheer the participants up by using their voice. Therefore, to make the participants aware of the presence of such external participant, they will be represented as avatars observing or cheering up the session from outside the game field (Figure 9).

(v) Belonging. In this example, participants are not allowed to choose the team they belong to since the therapist decides these teams in advance. Because of that reason, the system will make them aware of the team they belong to at the very beginning of the session through an audio message (Table 4).

(vi) Group goal. The participants have to be aware of their group goals. For example, considering as goal the coin they will have to touch, it could be communicated by means of both a visual message on the screen and an aural notification. Thanks to this double awareness, participants would have instant information about the goal as soon as it changes but they would always be able to watch it on the screen (at the top of Figure 3).

(vii) External motivation. When remote participants acting as motivators are monitoring the session, they can cheer the participants up. This can be done by using the three considered stimuli. First, they can make their avatars clap so that the participants could see and hear them. Moreover, this motivation may be also transmitted by using the motivators voice so that the patients will hear the encouragement voice messages of the remote participants. Finally, motivators may also send haptic commands. In that sense, patients will receive and feel a haptic pat on their shoulder.

(viii) Inner communication. If the therapist decided so, the participants will be able to communicate with their teammate by using their voice. Hence, if this interaction is enabled and the system detected that one participant is not speaking at all, an audio message will inform such participant that his/her voice will be heard by the other team member (Table 4).

(ix) Outer communication. Once again, the therapist can decide whether participants can interact verbally with the external participants as well as with the therapist himself/herself. Once again, the system can remind the participants that their voice will be heard by those external participants. Moreover, the therapist will be also able to see a VU meter corresponding to each participant's microphone to be aware visually when a patient is speaking (Figure 9). 
Thanks to the implementation of these awareness elements, as well as the others belonging to the present, past, and future concerns, participants will be able to interact with a rehabilitation system like the one presented at the beginning of this section. This will enable collaboration with remote participants, and it will enable the therapist to monitor and adapt the therapies to the participants needs.

\section{Conclusions and Future Work}

In order to achieve a proper collaboration while interacting with remote participants, they have to be aware of their collaborators (i.e., what they are doing, where they are, etc.). Therefore, dealing with awareness information properly is paramount for the success of a collaborative system. This issue is even more crucial when dealing with rehabilitation systems, whose participants may suffer from any cognitive or physical disability. This turns awareness information into a cornerstone of telerehabilitation systems, where awareness may lead to a suitable interaction. In order to guide the identification of such awareness requirements when developing cognitive and physical rehabilitation systems, an already existing awareness interpretation, namely, Gamespace Awareness [29], has been chosen as the foundation of our proposal. Such awareness interpretation was initially developed to deal with the awareness requirements of collaborative games. In this work, it has been adapted to make it suitable for rehabilitation systems featuring the monitoring of patients by using mobile sensors and providing feedback by using different kinds of stimuli (visual, aural, and haptic). This new interpretation comprises 39 awareness elements (classified into 4 different concerns) that will provide both patients and therapists with the required awareness information to ease collaborative and remote rehabilitation therapies. Furthermore, along with such collection of elements, the awareness interpretation provides a series of specific questions which will help designers and developers of new rehabilitation systems to identify awareness requirements properly. Moreover, we also provide recommendation of which feedback stimuli could be used to provide each awareness element (visual, aural, or haptic), as well as implementation examples for gathering and providing each one. Finally, in order to ease the usage of this awareness element in the development of a new rehabilitation system, a series of guidelines have been provided (Section 3.1).

In order to exemplify the awareness interpretation defined for this type of systems, a case study has been presented (Section 4). It describes several participants while performing a collaborative physical and cognitive rehabilitation exercise. The interaction with the system is performed by means of motion-sensing devices that translate the participants' movements into avatars' movements in the virtual world. Moreover, biometric devices and emotional analysis software are used to make the therapist aware of the patients' physical and emotional status.

It is worth noting that the game presented as case study is just a prototype. Therefore, as a future work, the final game will be implemented. Indeed, to perform this implementation, the postgame user interfaces will be implemented. This functionality will enable therapists to follow the evolution of their patients towards a successful rehabilitation. With the game fully implemented, it will be integrated with our rehabilitation management system to enable us to start the testing of such game by involving real users.

\section{Disclosure}

This paper is an extension of Teruel et al. [35].

\section{Conflicts of Interest}

The authors declare that they have no conflicts of interest.

\section{Acknowledgments}

This work was partially supported by Spanish Ministry of Economy, Industry and Competitiveness, State Research Agency/European Regional Development Fund, under Grants Vi-SMARt TIN2016-79100-R and HA-SYMBIOSIS TIN2015-72931-EXP.

\section{References}

[1] H. Oh, C. Rizo, and M. Enkin, "What is eHealth (3): a systematic review of published definitions," Journal of Medical Internet Research, vol. 7, no. 1, 2005.

[2] A. D. Black, J. Car, C. Pagliari et al., "The impact of ehealth on the quality and safety of health care: a systematic overview," PLoS Medicine, vol. 8, no. 1, Article ID e1000387, 2011.

[3] D. M. Brennan, S. Mawson, and S. Brownsell, "Telerehabilitation: enabling the remote delivery of healthcare, rehabilitation, and self management," in Studies in Health Technology and Informatics, pp. 231-248, 2015, http://www.ncbi.nlm.nih.gov/ pubmed/19592797.

[4] European Commission Information Society and Media, ICT for Health and i2010: Transforming the European healthcare landscape towards a strategy for ICT for Health, European Comission, Luxembourg, 2006.

[5] E. Doig, J. Fleming, and P. Kuipers, "Achieving Optimal Functional Outcomes in Community-Based Rehabilitation following Acquired Brain Injury: A Qualitative Investigation of Therapists' Perspectives," British Journal of Occupational Therapy, vol. 71, no. 9, pp. 360-370, 2008.

[6] C. Gutwin and S. Greenberg, "A Descriptive Framework of Workspace Awareness for Real-Time Groupware," Computer Supported Cooperative Work (CSCW), vol. 11, no. 3-4, pp. 411446, 2002.

[7] C. Gutwin and S. Greenberg, "Effects of awareness support on groupware usability," in Proceedings of the the SIGCHI conference, pp. 511-518, Los Angeles, California, United States, April 1998.

[8] D. M. Brennan, A. C. Georgeadis, C. R. Baron, and L. M. Barker, "The Effect of Videoconference-Based Telerehabilitation on Story Retelling Performance by Brain-Injured Subjects and Its Implications for Remote Speech-Language Therapy," Telemedicine Journal and e-Health, vol. 10, no. 2, pp. 147-154, 2004.

[9] Y. Chang, S. Chen, and J. Huang, "A Kinect-based system for physical rehabilitation: a pilot study for young adults with motor 
disabilities," Research in Developmental Disabilities, vol. 32, no. 6, pp. 2566-2570, 2011.

[10] H. G. Hoffman, A. Hollander, K. Schroder, S. Rousseau, and T. Furness, "Physically touching and tasting virtual objects enhances the realism of virtual experiences," Virtual Reality, vol. 3, no. 4, pp. 226-234, 1998.

[11] R. T. Wertz, N. F. Dronkers, E. Bernstein-Ellis, Y. Shubitowski, R. Elman, and G. K. Shenaut, Appraisal and Diagnosis of Neurogenic Communication Disorders in Remote Settings, Clinical Aphasiology, vol. 17, 1987.

[12] G. Pison, 1914-2014: A century of change in the French population pyramid, vol. 509, Institut National d'Études Démographiques (INED), 2014.

[13] M. Sandlund, E. L. Waterworth, and C. Häger, "Using motion interactive games to promote physical activity and enhance motor performance in children with cerebral palsy," Developmental Neurorehabilitation, vol. 14, no. 1, pp. 15-21, 2011.

[14] O. Gervasi, R. Magni, and M. Zampolini, "Nu!RehaVR: virtual reality in neuro tele-rehabilitation of patients with traumatic brain injury and stroke," Virtual Reality, vol. 14, no. 2, pp. 131$141,2010$.

[15] A. Cagnin, N. Jelcic, M. Agostini et al., Feasibility and efficacy of cognitive telerehabilitation in early Alzheimeramp;rsquo;s disease: aamp;nbsp;pilot study, Clinical Interventions in Aging, 2014.

[16] D. M. Brennan and L. M. Barker, "Human factors in the development and implementation of telerehabilitation systems," Journal of Telemedicine and Telecare, vol. 14, no. 2, pp. 55-58, 2008.

[17] I. Dimbwadyo-Terrer, A. de los Reyes-Guzmán, A. BernalSahún et al., "Virtual Reality System Toyra: A New Tool to Assess and Treatment for Upper Limb Motor Impairment in Patients with Spinal Cord Injury," in Converging Clinical and Engineering Research on Neurorehabilitation, vol. 1 of Biosystems \& Biorobotics, pp. 853-858, Springer Berlin Heidelberg, Berlin, Heidelberg, 2013.

[18] G. Kurillo, J. J. Han, A. Nicorici, and R. Bajcsy, “Tele-MFAsT: Kinect-Based Tele-Medicine Tool for Remote Motion and Function Assessment," in Studies in Health Technology and Informatics, pp. 215-221, IOS Press, 2014.

[19] T. Lisa, "The use of multisensory environment in acquired brain injury," in Proceedings of the The 2012 Annual Autumn Conference of the British Association of Neuroscience Nurses, Edinburgh, Scotland, 2012.

[20] M. Pirovano, R. Mainetti, G. Baud-Bovy, P. L. Lanzi, and N. A. Borghese, "Self-adaptive games for rehabilitation at home," in Proceedings of the 2012 IEEE Conference on Computational Intelligence and Games (CIG), pp. 179-186, Granada, Spain, September 2012.

[21] V. López-Jaquero and F. Montero, "Specifying How to Motivate People in Computer Assisted Rehabilitation," in Ubiquitous Computing and Ambient Intelligence, vol. 10069 of Lecture Notes in Computer Science, pp. 99-110, Springer International Publishing, Cham, 2016.

[22] M. A. Gutiérrez, F. Vexo, and D. Thalmann, Stepping into Virtual Reality, Springer London, London, 2008.

[23] A. D. Cheok, X. Yang, Z. Z. Ying, M. Billinghurst, and H. Kato, "Touch-space: mixed reality game space based on ubiquitous, tangible, and social computing," Personal and Ubiquitous Computing, vol. 6, no. 5-6, pp. 430-442, 2002.

[24] K. Cranen, C. H. Drossaert, E. S. Brinkman, A. L. BraakmanJansen, M. J. IJzerman, and M. M. Vollenbroek-Hutten, "An exploration of chronic pain patients' perceptions of home telerehabilitation services," Health Expectations, vol. 15, no. 4, pp. 339-350, 2012.

[25] J. Cason, "A Pilot Telerehabilitation Program: Delivering Early Intervention Services to Rural Families," International Journal of Telerehabilitation, vol. 1, no. 1, 2009.

[26] Y. Huang and Y. Hsu, "Social networking-based personal home telehealth system: A pilot study," Journal of Clinical Gerontology and Geriatrics, vol. 5, no. 4, pp. 132-139, 2014.

[27] R. Llorens, M. Alcaniz, M. D. Navarro, J. Ferri, and E. Noe, "Selfawareness rehabilitation through a multi-touch virtual game board after acquired brain injury," in Proceedings of the 2013 International Conference on Virtual Rehabilitation (ICVR), pp. 134-138, Philadelphia, PA, USA, August 2013.

[28] J. Grudin and S. Poltrock, "Taxonomy and theory in computer supported cooperative work," in The Oxford Handbook of Organizational Psychology, S. W. J. Kozlowski, Ed., pp. 13231348, Oxford University Press, 2012.

[29] M. A. Teruel, E. Navarro, P. González, V. López-Jaquero, and F. Montero, "Applying thematic analysis to define an awareness interpretation for collaborative computer games," Information and Software Technology, vol. 74, pp. 17-44, 2016.

[30] M. A. Teruel, E. Navarro, and P. González, "Towards an Awareness Interpretation for Physical and Cognitive Rehabilitation Systems," in Ubiquitous Computing and Ambient Intelligence, vol. 10069 of Lecture Notes in Computer Science, pp. 121-132, Springer International Publishing, Cham, 2016.

[31] J. Cusveller, C. Gerritsen, and J. de Man, "Evoking and Measuring Arousal in Game Settings," in Games for Training, Education, Health and Sports, vol. 8395 of Lecture Notes in Computer Science, pp. 165-174, Springer International Publishing, Cham, 2014.

[32] H. Joho, J. M. Jose, R. Valenti, and N. Sebe, "Exploiting facial expressions for affective video summarisation," in Proceedings of the Proceeding of the ACM International Conference, p. 1, Santorini, Fira, Greece, July 2009.

[33] M. A. Teruel, E. Navarro, V. López-Jaquero, F. Montero, and P. González, "A comprehensive framework for modeling requirements of CSCW systems," Journal of Software: Evolution and Process, vol. 29, no. 5, p. e1858, 2017.

[34] F. Montero, V. López-Jaquero, E. Navarro, E. Sánchez, V. LópezJaquero, and E. Sánchez, "Computer-Aided Relearning Activity Patterns for People with Acquired Brain Injury," Computers \& Education, vol. 57, pp. 1149-1159, 2011.

[35] M. A. Teruel, E. Navarro, and P. González, “Towards an Awareness Interpretation for Physical and Cognitive Rehabilitation Systems," in Ubiquitous Computing and Ambient Intelligence, C. R. García, P. Caballero-Gil, M. Burmester, and A. QuesadaArencibia, Eds., pp. 121-132, Springer International Publishing, 2016. 

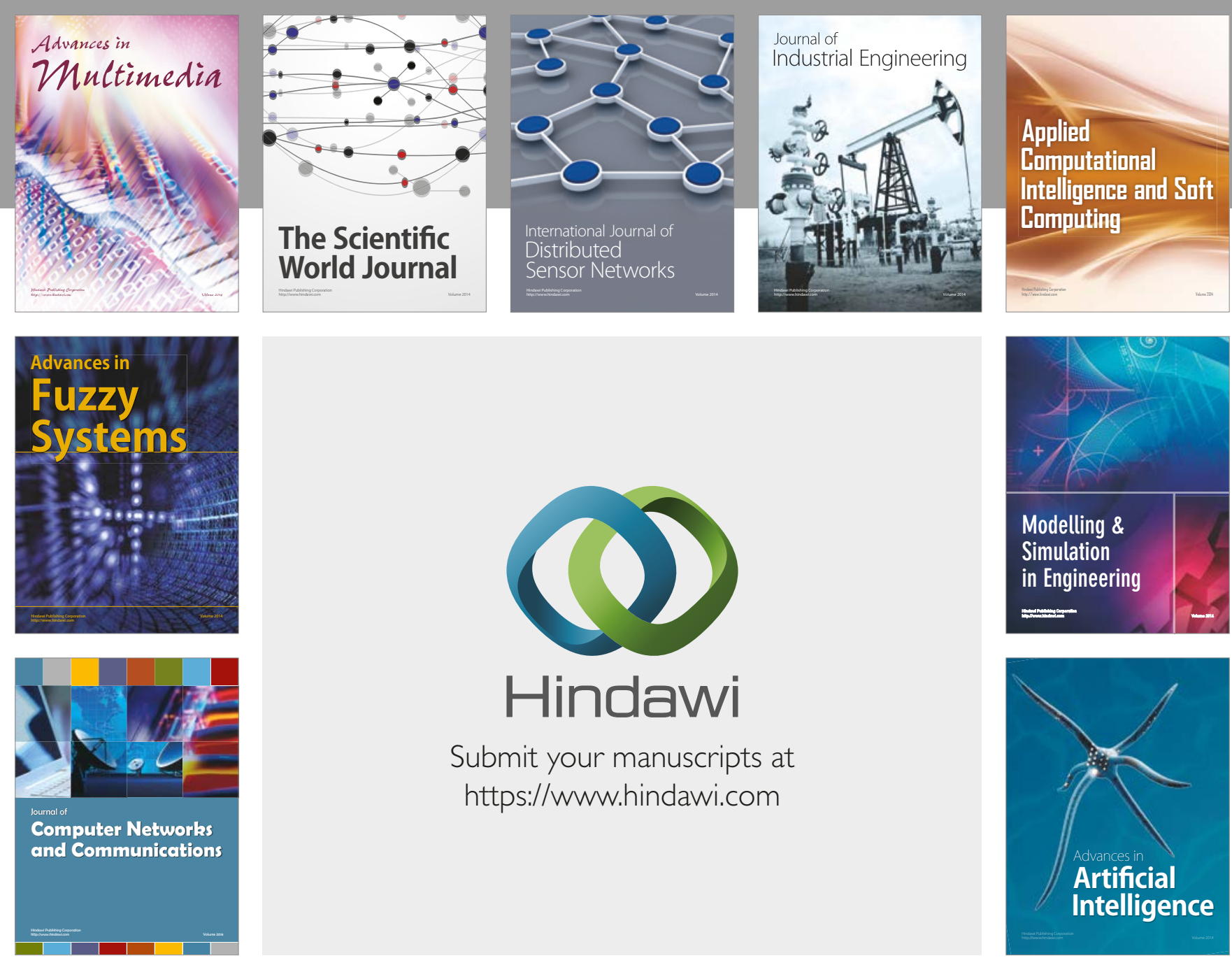

\section{Hindawi}

Submit your manuscripts at

https://www.hindawi.com
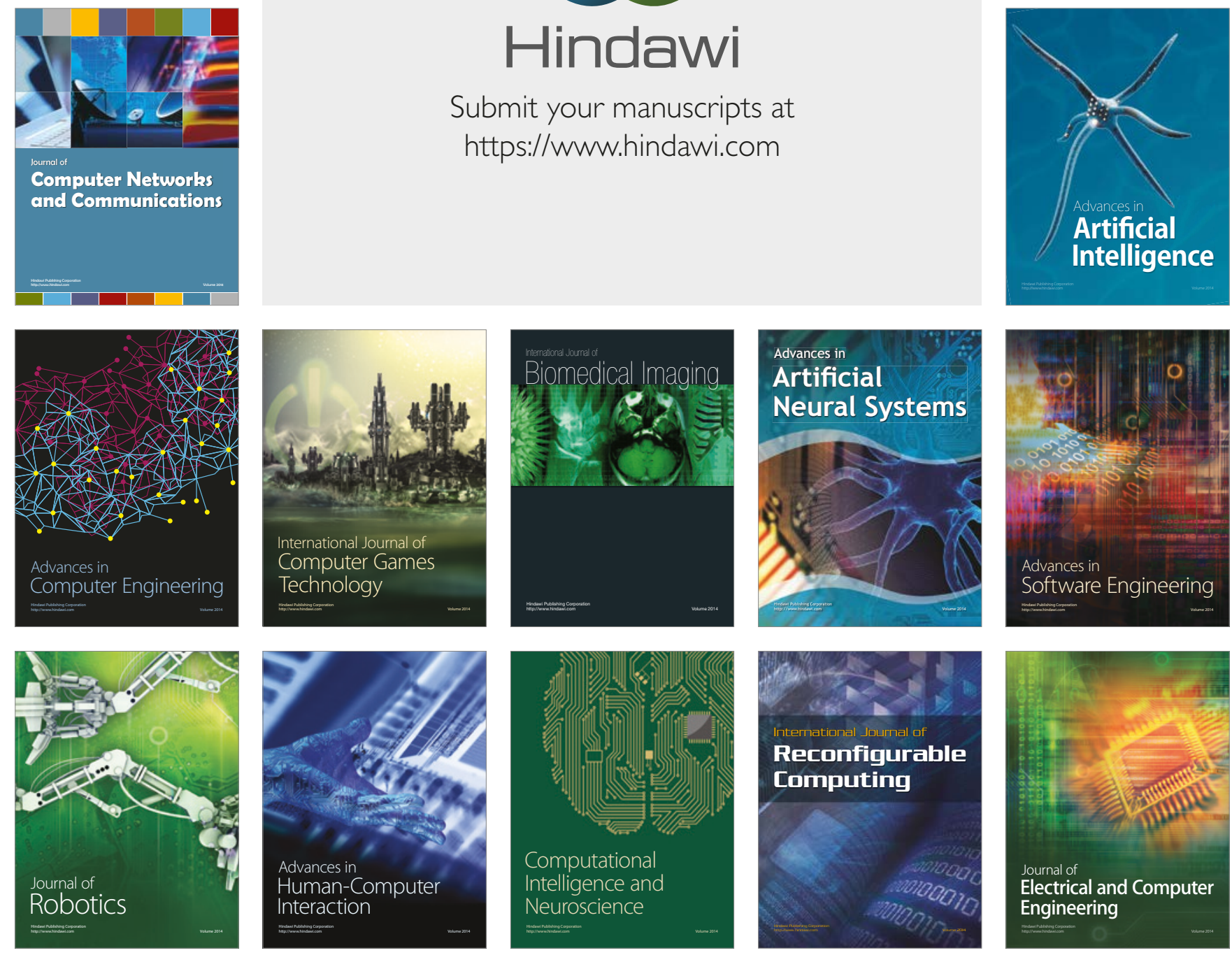